\title{
Myocardial dysfunction in patients with type 2 diabetes mellitus: role of endothelial progenitor cells and oxidative stress
}

\author{
Chun Ting Zhao ${ }^{1,2,3}$, Mei Wang ${ }^{2,4}$, Chung Wah Siu' ${ }^{2,4}$, Ying Long Hou', Tian Wang ${ }^{3}$, Hung Fat Tse ${ }^{2,4^{*}}$ \\ and Kai Hang $\mathrm{Yiu}^{2,4^{*}}$
}

\begin{abstract}
Background: Endothelial progenitor cells (EPCS) are responsible for angiogenesis and maintenance of microvascular integrity, the number of EPCs is correlated with oxidative stress. Their relation to myocardial dysfunction in patients with type 2 diabetes mellitus (T2DM) is nonetheless unknown.

Methods: Eighty-seven patients with T2DM and no history of coronary artery disease were recruited. Transthoracic echocardiography and detailed evaluation of left ventricular (LV) systolic function by 2-dimensional (2D) speckle tracking derived strain analysis in 3 orthogonal directions was performed. Four subpopulations of EPCs, including CD34+, CD133+, CD34+/kinase insert domain-containing receptor (KDR) + and CD133+/KDR + EPCs, were measured by flow cytometry. Oxidative stress was assessed by superoxide dismutase (SOD).
\end{abstract}

Results: The mean age of the patients was $62 \pm 9$ years and 39.6\% were male. Those with an impaired longitudinal strain had a lower number of CD34+ EPCs $(2.82 \pm 1.87 \%$ vs. $3.74 \pm 2.12 \%, P<0.05)$ than those with preserved longitudinal strain. When compared with those with preserved circumferential strain, patients with an impaired circumferential strain had a lower number of CD34+ EPCs (2.63 $\pm 1.80 \%$ vs. $3.87 \pm 2.10 \%, P<0.01)$ and SOD level $(0.13 \pm 0.06 \mathrm{U} / \mathrm{ml}$ vs. $0.20 \pm 0.08 \mathrm{U} / \mathrm{ml}, \mathrm{P}<0.01)$. Patients with an impaired radial strain nonetheless had a lower number of CD34+ EPCs ( $2.62 \pm 2.08 \%$ vs. $3.69 \pm 1.99 \%$, P < 0.05). Multivariate analysis demonstrated that only impaired global circumferential strain remained significantly associated with CD34 + EPCs and SOD.

Conclusions: LV global circumferential strain was independently associated with number of CD34+ EPCS and SOD. These findings suggest that myocardial dysfunction in patients with T2DM is related to depletion of EPCS and increased oxidative stress.

Keyword: Type 2 diabetes mellitus, Myocardial injury, Endothelial progenitor cells

\section{Introduction}

Type 2 diabetes mellitus (T2DM) is associated with myocardial dysfunction, independent of underlying coronary artery disease. Patients with T2DM have a 2-5 fold higher risk of developing heart failure than those without $[1,2]$. Although the pathology of myocardial dysfunction in these patients is unclear, it is likely

\footnotetext{
* Correspondence: hftse@hkucc.hku.hk; khkyiu@hotmail.com ${ }^{2}$ Division of Cardiology, Department of Medicine, the University of Hong Kong, Queen Mary Hospital, Rm 1929b, Block K, Hong Kong, China ${ }^{4}$ Research Centre of Heart, Brain, Hormone and Healthy Aging, Li Ka Shing Faculty of Medicine, the University of Hong Kong, Hong Kong, China Full list of author information is available at the end of the article
}

multifactorial and includes increased oxidative stress, [3] microangiopathy, [4] and altered myocardial metabolism and structure with fibrosis [5].

Increasing evidence is emerging to support the role of endothelial progenitor cells(EPCs), [6] a subpopulation of mononuclear cells that possess the ability for vascular repair and neovascularization, in microangiopathy and myocardial dysfunction in patients with T2DM $[7,8]$. In addition, EPCs have been shown to be closely related with oxidative stress, that also contributes to myocardial dysfunction in these patients. Recent studies have demonstrated that 2-dimensional (2D) speckle tracking derived strain analysis is a sensitive method to detect 
systolic dysfunction in T2DM patients with an apparently normal left ventricular (LV) ejection fraction $[9,10]$. Nevertheless the association of EPCs and oxidative stress with LV myocardial function in patients with T2DM has not been evaluated. The aim of the present study is to determine the relationship of EPCs and oxidative stress, as determined by superoxide dismutase (SOD), to myocardial function measured by 2D speckle tracking LV strain.

\section{Method}

\section{Study population}

A total of 110 consecutive patients with T2DM as defined by World Health Organization criteria and no coronary artery disease were recruited at Queen Mary Hospital from January 2008 to January 2010. Patients were excluded if they had a documented history or clinical symptoms and signs of macrovascular disease including myocardial infarction, coronary artery disease, stroke or peripheral vascular disease. Patients with dilated cardiomyopathy, New York Heart Association class III/IV heart failure, significant renal dysfunction with creatinine level $>220 \mathrm{umol} / \mathrm{L}$, liver failure or clinical/biochemical evidence of concomitant inflammatory disease or patients who declined to participate were also excluded. As a result, 87 subjects were eligible for this study. The current study is in compliance with the Helsinki Declaration and has been approved by the Hong Kong West Cluster Ethics Committee. All patients had a written informed consent.

\section{Study design}

Baseline demographic data and cardiovascular medications were recorded in all subjects. Hypertension was defined as resting systolic or diastolic blood pressure $\geq 140$ $190 \mathrm{mmHg}$ on two occasions or the prescription of antihypertensive medication. Hypercholesterolemia was defined as fasting total plasma cholesterol level $\geq 4.9 \mathrm{mmol} / \mathrm{L}$ or the prescription of lipid-lowering medication [11]. Smoking status was recorded as ever-smoker (past or current) or non-smoker. Body height, weight and blood pressure were measured as previously described [12]. Body-mass index (BMI) was calculated as $\mathrm{kg} / \mathrm{m}^{2}$. Fasting blood samples were obtained to measure serum total cholesterol, triglyceride, low-density lipoproteincholesterol (LDL-C), high-density lipoprotein-cholesterol (HDL-C), glucose, HbA1c, creatinine, and high sensitivity C-reactive protein (hs-CRP).

After mixing, samples were centrifuged at $3000 \mathrm{rpm}$ for 20 minutes and the supernatants frozen at $-80^{\circ} \mathrm{C}$ until assay. Oxidative stress was measured as superoxide dismutase (SOD), a potent antioxidant enzyme [13].

\section{Flow cytometry}

Four subpopulations of EPCs, including CD34+, CD133 + , CD34+/kinase insert domain-containing receptor $(\mathrm{KDR})+$ and CD133+/KDR + EPCs, were measured by flow cytometry. Fluorescence-activated cell analysis was performed to determine the number of EPCs as described previously [14]. Briefly, $100 \mu \mathrm{l}$ of peripheral blood was incubated with a phycoerythrin-conjugated monoclonal antibody against human KDR (Sigma, St Louis, MO, USA), followed by a fluorescein isothiocyanate (FITC)-conjugated CD34 and CD133 antibody (Beckman Coulter, Fullerton, CA, USA). FITC-labelled anti-human CD45 antibody was used for differential gating during flow analysis. FITC-labelled IgG1a (Beckman Coulter) and phycoerythrin-labelled IgG2b (Becton Dickinson, Franklin Lakes, NJ, USA) served as the isotypic control for colour compensation. Analysis was performed with an automated fluorescence-activated cell counter (Elite; Beckman Coulter) in which 1000000 events were counted. The absolute number of cells expressing CD34+, CD133+, CD34/KDR + CD133/KDR + per 1000000 events in the lymphocyte gate was calculated. The percentages of all the measured components were derived from the absolute cell count divided by the lymphocyte count [15].

\section{Echocardiography}

Transthoracic echocardiography was performed in all patients using a commercially available system (Vingmed Vivid 7, General Electric Vingmed Ultrasound, Milwaukee, USA). A $3.5-\mathrm{MHz}$ transducer was used to obtain images that were digitally stored in cineloop format (5 cardiac cycles). Measurements were performed offline using EchoPAC version 108.1.5 (General Electric - Vingmed, Horten, Norway). The interventricular septum thickness, posterior wall thickness, and LV dimensions were measured in M-modal according to the current recommendation. LV volume and ejection fraction was determined from apical four and two-chamber views using the modified Simpson's biplane method of discs. Evaluation of LV diastolic function was based on the pulsed-wave Doppler of mitral valve inflow. Peak velocity in early diastole (E-wave) and late diastole (A-wave) was measured and the E/A ratio calculated. Pulsed wave tissue Doppler imaging was used to measure the early diastolic velocity (E') with the sample volume placed at lateral annulus. In addition, E/E' ratio was calculated as an estimation of LV filling pressure [16]. LV diastolic dysfunction was therefore classified as previously described [17].

\section{Two-dimensional speckle tracking strain analysis}

Two-dimensional speckle tracking strain analysis allows detailed assessment of LV myocardial deformation by 
tracking natural acoustic markers (speckles) in a frameto-frame basis within the cardiac cycle. LV deformation can be evaluated in three orthogonal directions as longitudinal, circumferential and radial strains [18].

Longitudinal strain, assessing the shortening/lengthening of the myocardial wall, was measured from the 3 apical views: 2-chamber view (comprising anterior and inferior walls), 4-chamber view (posteroseptal and lateral walls) and long axis view (anteroseptal and posterior walls). Each wall was subsequently divided into 3 levels (basal, mid and apical) and a total of 18 segmental strain curves were obtained. Global longitudinal strain was calculated as the mean of the peak systolic strain value of the 18 segments.

From LV mid-ventricular short-axis view, both circumferential strain (evaluating myocardial shortening/lengthening along LV curvature) and radial strain (evaluating myocardial thickening/thinning) were measured. The global value of circumferential and radial strains were derived from the average peak systolic strain value of 6 segments. Global longitudinal and circumferential strains are expressed as negative values, and a lower strain is represented by less negative values. Global radial strain is expressed as a positive value: a lower value indicates lower strain.

Impairment of the 3-orthogonal directional global strains was defined as mean \pm 2 standard deviations according to the results of a recent study that assessed global strains in healthy Asian subjects using the same vendor machine as the current study [19]. Thus in this study impaired global longitudinal strain is defined as >-17.1\%; impaired global circumferential strain $>-17.0 \%$ and; impaired radial strain $<29.4 \%$.

The interobserver and intraobserver variability for longitudinal, radial, and circumferential strains were $6.5 \%$ and $2.6 \%, 10.4 \%$ and $7.6 \%, 4.9 \%$ and $2.4 \%$, respectively.

\section{Statistical analysis}

All continuous variables and categorical variables are expressed as mean \pm standard deviation and frequencies or proportions, respectively. Continuous demographic variables were compared using the Mann-Whitney $U$ test and categorical demographic variables were compared using Pearson Chi-square test or the Fisher's exact test if at least one cell had an expected cell count below five. Correlation coefficients were performed in order to assess the association of circulating EPCs and oxidative stress with myocardial function in T2DM patients. Multivariate analyses were performed to detect the predictors for abnormal myocardial function. To avoid multi-collinearity, multi-directional strains were entered individually into the model. All statistical analyses were performed using the statistical package SPSS for windows (Version 18.0, SPSS, Chicago, USA). All P values reported are 2 -sided for consistency. A P value $<0.05$ was considered statistically significant.

\section{Results}

Baseline characteristics

The baseline characteristics of all patients are shown in Table 1. All patients had normal LV dimension and function including LV end diastolic volume (mean $80 \pm$ $19 \mathrm{ml}), \mathrm{LV}$ end systolic volume $(30 \pm 12 \mathrm{ml})$ and LV ejection fraction $(64 \pm 7 \%)$. Diastolic dysfunction was noted in 69 patients $(79 \%)$ and the mean E/E' ratio was $9.9 \pm$ 2.6. The mean global longitudinal, circumferential and radial strains were $17.6 \pm 2.5 \%, 17.7 \pm 2.2 \%$ and $33.7 \pm$ $11.0 \%$, respectively. According to the pre-defined cut-off values, $39 \%$ of patients had impaired global longitudinal strain; 39\% had impaired radial strain; and 30\% had impaired radial strain.

\section{Clinical demographics in patients with and without impaired strains}

The clinical demographics of patients with and without impaired LV strain are shown in Table 1. Patients with an impaired longitudinal strain had a higher BMI, HbA1c level and a lower number of CD34+ EPCs than those with preserved longitudinal strain. When compared with those with preserved circumferential strain, patients with an impaired circumferential strain had a lower CD34+ EPCs and SOD level. Patients with an impaired radial strain nonetheless had a lower number of CD34+ EPCs compared with those with preserved radial strain.

\section{Correlation of global strains with clinical demographics}

The correlation between the 3 orthogonal directional strains and clinical demographics is shown in Table 2. Global longitudinal and radial strains were both negatively correlated with BMI. Global circumferential and radial strains were correlated with CD34+ EPCs. Only circumferential strain was negatively correlated with serum level of SOD. In addition, level of CD34+ EPCs was significantly correlated with serum level of SOD $(\mathrm{R}=0.37, P<0.01)$. Nonetheless CD133+ $(\mathrm{R}=0.13$, $P=0.30), \mathrm{CD} 34+/ \mathrm{KDR}+(\mathrm{R}=0.09, P=0.50)$ and $\mathrm{CD} 133$ $+/ \mathrm{KDR}+\mathrm{EPCs} \quad(\mathrm{R}=0.11, \quad P=0.41)$ showed no such correlation.

\section{Association of endothelial progenitor cells and superoxide dismutase with global strains}

Univariate analysis revealed that impaired circumferential and radial strains were associated with CD34+ EPC level and impaired global longitudinal, circumferential and radial strains were related to SOD (Table 3). In order to evaluate the relation of impaired global strains 
Table 1 Clinical demographics in patients with and without impaired strains

\begin{tabular}{|c|c|c|c|c|c|c|c|}
\hline \multirow[t]{2}{*}{ Variables } & \multirow[t]{2}{*}{$\begin{array}{l}\text { All patients } \\
(\mathrm{n}=87)\end{array}$} & \multicolumn{2}{|c|}{$\begin{array}{l}\text { Longitudinal strain } \\
\text { (cutoff }-17.1 \% \text { ) }\end{array}$} & \multicolumn{2}{|c|}{$\begin{array}{l}\text { Circumferential strain } \\
\text { (cutoff }-17.0 \% \text { ) }\end{array}$} & \multicolumn{2}{|c|}{$\begin{array}{l}\text { Radial strain } \\
\text { (cutoff } 29.4 \% \text { ) }\end{array}$} \\
\hline & & $\begin{array}{l}\text { Preserved } \\
(n=53)\end{array}$ & $\begin{array}{l}\text { Impaired } \\
(n=34)\end{array}$ & $\begin{array}{l}\text { Preserved } \\
(n=53)\end{array}$ & $\begin{array}{l}\text { Impaired } \\
(\mathrm{n}=34)\end{array}$ & $\begin{array}{l}\text { Preserved } \\
(n=62)\end{array}$ & $\begin{array}{c}\text { Impaired } \\
(n=25)\end{array}$ \\
\hline Age, years & $61.8 \pm 9.3$ & $60.5 \pm 9.7$ & $63.9 \pm 8.2$ & $61.4 \pm 10.1$ & $62.5 \pm 7.9$ & $61.3 \pm 9.7$ & $62.9 \pm 8.3$ \\
\hline Male gender, \% (n) & $39.6(36)$ & $42.9(24)$ & $34.3(12)$ & $33.9(19)$ & $48.6(17)$ & $59.7(37)$ & $64.0(16)$ \\
\hline $\mathrm{BMI}, \mathrm{kg} / \mathrm{m}^{2}$ & $25.7 \pm 4.3$ & ${ }^{*} 25.01 \pm 4.2$ & $26.9 \pm 4.2$ & $25.3 \pm 4.0$ & $26.3 \pm 4.7$ & $25.2 \pm 4.4$ & $26.9 \pm 4.2$ \\
\hline $\mathrm{SBP}, \mathrm{mmHg}$ & $137 \pm 16$ & $137 \pm 16$ & $138 \pm 16$ & $138 \pm 15$ & $138 \pm 17$ & $136 \pm 16$ & $141 \pm 16$ \\
\hline $\mathrm{DBP}, \mathrm{mmHg}$ & $78 \pm 8$ & $78 \pm 8$ & $78 \pm 8$ & $77 \pm 9$ & $78 \pm 7$ & $77 \pm 8$ & $79 \pm 8$ \\
\hline Duration of disease, years & $9.9 \pm 7.7$ & $8.9 \pm 8.0$ & $11.8 \pm 7.0$ & $8.9 \pm 6.9$ & $11.7 \pm 8.9$ & $10.4 \pm 8.2$ & $9.0 \pm 7.2$ \\
\hline Insulin therapy, \% (n) & 19.8(18) & ${ }^{*} 37.1(13)$ & $8.9(5)$ & 19.6(11) & $20.0(7)$ & $17.7(11)$ & $24.0(6)$ \\
\hline Smoker, \% (n) & 17.6(16) & $17.9(10)$ & $17.1(6)$ & 16.1(9) & $20.0(7)$ & $14.5(9)$ & $20.0(5)$ \\
\hline Hypertension, \% (n) & $60.4(55)$ & $57.1(32)$ & $65.7(23)$ & $57.1(32)$ & $65.7(23)$ & 61.3(38) & $52.0(13)$ \\
\hline Total cholesterol, mmol/L & $4.9 \pm 0.8$ & $5.02 \pm 0.90$ & $4.83 \pm 0.73$ & $5.01 \pm 0.85$ & $4.84 \pm 0.82$ & $4.97 \pm 0.86$ & $4.95 \pm 0.78$ \\
\hline Triglycerides, mmol/L & $1.4 \pm 0.8$ & $1.36 \pm 0.80$ & $1.42 \pm 0.75$ & $1.43 \pm 0.79$ & $1.31 \pm 0.77$ & $1.32 \pm 0.77$ & $1.53 \pm 0.81$ \\
\hline High density lipoprotein, mmol/L & $1.4 \pm 0.4$ & $1.39 \pm 0.37$ & $1.44 \pm 0.45$ & $1.40 \pm 0.36$ & $1.42 \pm 0.45$ & $1.42 \pm 0.45$ & $1.40 \pm 0.24$ \\
\hline Low density lipoprotein, mmol/L & $2.9 \pm 0.7$ & $3.01 \pm 0.75$ & $2.72 \pm 0.62$ & $2.95 \pm 0.70$ & $2.83 \pm 0.74$ & $2.93 \pm 0.71$ & $2.86 \pm 0.72$ \\
\hline Fasting glucose, mmol/L & $7.57 \pm 2.07$ & $7.19 \pm 1.78$ & $8.11 \pm 2.34$ & $7.49 \pm 2.31$ & $7.68 \pm 1.68$ & $7.68 \pm 2.19$ & $7.52 \pm 1.70$ \\
\hline Creatinine, umol/L & $77.1 \pm 25.1$ & $76.8 \pm 27.58$ & $77.6 \pm 21.1$ & $77.3 \pm 28.5$ & $76.8 \pm 19.0$ & $74.1 \pm 15.9$ & $77.1 \pm 23.6$ \\
\hline hs-CRP, mg/L & $1.49 \pm 2.18$ & $1.36 \pm 1.75$ & $1.72 \pm 2.80$ & $1.65 \pm 2.71$ & $1.27 \pm 0.98$ & $1.33 \pm 1.68$ & $1.90 \pm 3.09$ \\
\hline $\mathrm{SOD}, \mathrm{U} / \mathrm{ml}$ & $0.17 \pm 0.08$ & $0.18 \pm 0.09$ & $0.15 \pm 0.06$ & ${ }^{* *} 0.20 \pm 0.08$ & $0.13 \pm 0.06$ & $0.17 \pm 0.09$ & $0.16 \pm 0.08$ \\
\hline $\mathrm{HbA} 1 \mathrm{c}, \%$ & $7.72 \pm 1.24$ & ${ }^{*} 7.51 \pm 1.22$ & $8.07 \pm 1.20$ & $7.70 \pm 1.21$ & $7.75 \pm 1.30$ & $7.83 \pm 1.32$ & $7.54 \pm 1.00$ \\
\hline CD34+ EPCs, \% & $3.38 \pm 2.07$ & ${ }^{*} 3.74 \pm 2.12$ & $2.82 \pm 1.87$ & ${ }^{* *} 3.87 \pm 2.10$ & $2.63 \pm 1.80$ & *3.69 \pm 1.99 & $2.62 \pm 2.08$ \\
\hline CD133+ EPCs, \% & $0.44 \pm 0.45$ & $0.44 \pm 0.47$ & $0.45 \pm 0.43$ & $0.50 \pm 0.49$ & $0.35 \pm 0.38$ & $0.46 \pm 0.47$ & $0.41 \pm 0.42$ \\
\hline CD34+/KDR + EPCs, \% & $0.85 \pm 0.69$ & $0.89 \pm 0.57$ & $0.78 \pm 0.85$ & $0.92 \pm 0.78$ & $0.74 \pm 0.52$ & $0.91 \pm 0.75$ & $0.70 \pm 0.49$ \\
\hline CD133+/KDR + EPCs, \% & $0.25 \pm 0.28$ & $0.25 \pm 0.30$ & $0.25 \pm 0.28$ & $0.28 \pm 0.32$ & $0.21 \pm 0.20$ & $0.28 \pm 0.32$ & $0.19 \pm 0.14$ \\
\hline
\end{tabular}

${ }^{*} \mathrm{P}<0.05 ;{ }^{*} \mathrm{P}<0.01$.

Abbreviations: $B M I=$ body mass index; $E P C s=$ endothelial progenitor cells; $D B P=$ diastolic blood pressure; $h s-C R P=H$ High sensitivity $C$-reactive protein; $S B P=$ systolic blood pressure; $S O D=$ superoxide dismutase.

with CD34+ EPCs and SOD, multivariate adjustment for age, gender, BMI, smoking history, hypertension, hypercholesterolaemia and HbA1c was performed. The results demonstrated that impaired global circumferential and radial strains were independently associated with CD34+ EPCs, whereas only impaired global circumferential strain was independently associated with SOD. When CD34+ EPCs and SOD were evaluated together, impaired global circumferential strain was the only LV strain that remained significantly associated with both $\mathrm{CD} 34+\mathrm{EPCs}$ (odd ratio $[\mathrm{OR}] .=0.64$, Confidence interval $[\mathrm{CI}]=0.43-0.95, \mathrm{P}=0.03)$ and $\mathrm{SOD}(\mathrm{OR}=0.001, \mathrm{CI}$ $=0.001-0.23, \mathrm{P}=0.02$ ).

\section{Discussion}

The present study demonstrated that at least 30\% of T2DM patients, with apparently normal LV dimensions and ejection fraction, have impaired myocardial function as measured by $2 \mathrm{D}$ speckle tracking derived strain. Importantly, LV global circumferential strain was independently associated with depletion of CD34+ EPCs and increased oxidative stress measured by SOD.

\section{Endothelial progenitor cells and myocardial dysfunction}

The pathogenesis of myocardial dysfunction is multifaceted, but includes activation of renin-angiotensin aldosterone system, [20] myocardial steatosis, [21] autonomic dysfunction [22] and increased myocardial fibrosis [23]. Microangiopathy nonetheless has been proposed to contribute to diabetic heart disease $[24,25]$.

The presence of diabetes induces thickening of the capillary basement membrane and endothelial swelling of the myocardium [26,27]. These changes give rise to microangiopathy as evidenced by microaneurysms, interstitial fibrosis, and perfusion defect by radiological study and finally result in myocardial dysfunction [28]. Preserving the integrity of the microvasculature, which is partly maintained by circulating EPCs, may thus prevent the development of diabetic heart disease. In addition to endothelial regeneration and postnatal 
Table 2 Correlation of the cardiovascular risk factors and global strains

\begin{tabular}{|c|c|c|c|c|c|c|}
\hline \multirow[t]{2}{*}{ Variables } & \multicolumn{2}{|c|}{ Longitudinal strain } & \multicolumn{2}{|c|}{ Circumferential strain } & \multicolumn{2}{|c|}{ Radial strain } \\
\hline & $\mathbf{R}$ & $P$ value & $\mathbf{R}$ & $P$ value & $\mathbf{R}$ & $P$ value \\
\hline Age & 0.19 & 0.08 & -0.01 & 0.92 & -0.15 & 0.17 \\
\hline BMI & 0.22 & ${ }^{*} 0.04$ & 0.19 & 0.09 & -0.32 & ${ }^{*} 0.003$ \\
\hline SBP & 0.08 & 0.44 & 0.08 & 0.50 & -0.14 & 0.21 \\
\hline DBP & 0.04 & 0.71 & 0.11 & 0.33 & -0.12 & 0.30 \\
\hline Duration of disease & 0.15 & 0.18 & 0.05 & 0.66 & 0.03 & 0.82 \\
\hline Total cholesterol & -0.04 & 0.74 & -0.08 & 0.48 & -0.05 & 0.67 \\
\hline Triglycerides & 0.13 & 0.23 & -0.05 & 0.67 & -0.15 & 0.18 \\
\hline High density lipoprotein & -0.03 & 0.81 & 0.03 & 0.76 & 0.03 & 0.78 \\
\hline Low density lipoprotein & -0.10 & 0.33 & -0.09 & 0.42 & 0.07 & 0.95 \\
\hline Fasting glucose & 0.10 & 0.38 & 0.07 & 0.57 & 0.01 & 0.92 \\
\hline Creatinine & 0.08 & 0.48 & 0.16 & 0.14 & -0.10 & 0.39 \\
\hline hs-CRP & 0.05 & 0.72 & -0.01 & 0.92 & -0.22 & 0.09 \\
\hline SOD & -0.23 & 0.07 & -0.32 & ${ }^{*} 0.01$ & 0.11 & 0.39 \\
\hline $\mathrm{HbA1c}$ & 0.07 & 0.50 & -0.12 & 0.29 & 0.07 & 0.53 \\
\hline CD34+ ECPs & -0.19 & 0.08 & -0.28 & ${ }^{*} 0.01$ & 0.21 & ${ }^{*} 0.049$ \\
\hline CD133+ EPCS & -0.02 & 0.86 & -0.08 & 0.47 & 0.02 & 0.86 \\
\hline CD34+/KDR + EPCs & -0.01 & 0.96 & -0.21 & 0.05 & 0.18 & 0.10 \\
\hline CD133+/KDR + EPCs & -0.07 & 0.54 & -0.16 & 0.14 & -0.02 & 0.87 \\
\hline
\end{tabular}

Abbreviations: $B M I=$ body mass index; $E P C s=$ endothelial progenitor cells; $D B P=$ diastolic blood pressure; $h s-C R P=$ High sensitivity $C$-reactive protein; $S B P=$ systolic blood pressure; $S O D=$ superoxide dismutase.

neovascularization in the ischemic region, the ability to differentiate into mature endothelial cells and be incorporated into new vessels enables EPCs to produce proangiogenic cytokines in a paracrine fashion to facilitate vascularization $[29,30]$. The clinical value of EPCs has been established in diabetic patients, and their depletion is associated with macrovascular disease such as increased arterial stiffness, [31] carotid intima media thickness, [32] brachial flow mediated dilatation [33] and peripheral artery disease [34,35]. Depletion of EPCs has also been shown to be predictive of future adverse cardiovascular events [36,37]. A study by Yoon and colleagues has shown that DiI labelled bone marrow derived EPCs contributed to myocardial microvasculature and function in rats with diabetic heart disease [4]. No studies have evaluated the role of EPCs with myocardial dysfunction in human subjects. The present study further demonstrated that EPCs in patients with T2DM and no atherosclerotic disease, were independently associated with myocardial dysfunction, measured by 2D speckle tracking strain. The current results thus suggest that depletion of EPCs contributes to the development of diabetic heart disease.

The present results indicate that CD34+ EPCs were most strongly correlated with myocardial dysfunction, compared with other subtypes of EPCs. Although the reason is uncertain, this could be partly explained by the ability of CD34+ EPCs to differentiate not only into hematopoietic stem cells, but also cardiomyocytes, smooth muscle and endothelial cells [38]. Previous studies have shown the CD34+ EPCs are best related with cardiovascular risk factors, metabolic syndrome [39] and long-term outcome compared with other subtypes of EPCs [36]. The multi-lineage property of CD34+ EPCs may thus provide a more comprehensive assessment of the pathophysiological development of diabetic heart disease.

\section{Oxidative stress and myocardial dysfunction}

Oxidative stress, represented by an overproduction of reactive oxygen species, plays a role in all stages of diabetic heart disease, ranging from cardiac hypertrophy to myocardial fibrosis and dysfunction [40]. Animal studies have shown that suppression of oxidative stress with coenzyme A10 (an antioxidant in its reduced form, ubiquinol-10) [41] and 3/,4/-dihydroxyflavonol (a synthetic flavonol) [42], improves cardiac function and reduces myocyte hypertrophy and collagen deposition in diabetic rats. The present results further demonstrate the independent role of SOD in relation to myocardial dysfunction, thus highlighting the role of oxidative stress in the development of diabetic heart disease. In a study of 23 patients with T2DM, SOD has been proven to play a role in modulating EPC function under hyperglycemic 
Table 3 Unadjusted and adjusted effects of superoxide dismutase (SOD) and CD34+ endothelial progenitor cells (EPCs) on global strains

\begin{tabular}{|c|c|c|c|c|c|c|}
\hline & \multicolumn{2}{|c|}{ Longitudinal strain } & \multicolumn{2}{|c|}{ Circumferential strain } & \multicolumn{2}{|c|}{ Radial strain } \\
\hline & OR (95\%) & $P$ value & OR $(95 \%)$ & $P$ value & OR (95\%) & $P$ value \\
\hline \multicolumn{7}{|l|}{ SOD } \\
\hline Uadjusted & $0.002(0.001,1.544)$ & $<0.01$ & $0.001(0.001,0.009)$ & $<0.01$ & $0.02(0.01,17.22)$ & 0.02 \\
\hline \#Adjusted & $0.001(0.000,1.353)$ & 0.060 & $0.002(0.001,0.007)$ & $<0.01$ & $0.004(0.001,7.868)$ & 0.15 \\
\hline \multicolumn{7}{|c|}{ CD34+ EPCs } \\
\hline Uadjusted & $0.81(0.65,1.02)$ & 0.07 & $0.71(0.55,0.92)$ & $<0.01$ & $0.75(0.57,0.98)$ & 0.03 \\
\hline \#Adjusted & $0.82(0.64-1.05)$ & 0.12 & $0.71(0.53,0.93)$ & 0.01 & $0.74(0.56,0.98)$ & 0.04 \\
\hline \multicolumn{7}{|c|}{ CD133+ EPCs } \\
\hline Uadjusted & $0.87(0.35,2.18)$ & 0.76 & $0.44(0.15,1.32)$ & 0.15 & $0.77(0.26,2.26)$ & 0.77 \\
\hline \#Adjusted & $0.51(0.18,1.46)$ & 0.21 & $0.38(0.12,1.20)$ & 0.10 & $0.46(0.14,1.58)$ & 0.22 \\
\hline \multicolumn{7}{|c|}{ CD34/KDR + EPCs } \\
\hline Uadjusted & $0.79(0.41,1.51)$ & 0.47 & $0.64(0.30,1.35)$ & 0.24 & $0.56(0.23,1.37)$ & 0.21 \\
\hline \#Adjusted & $0.71(0.36,1.42)$ & 0.33 & $0.66(0.30,1.49)$ & 0.32 & $0.50(0.19,1.33)$ & 0.17 \\
\hline \multicolumn{7}{|c|}{ CD133/KDR + EPCs } \\
\hline Uadjusted & $0.72(0.17,3.12)$ & 0.66 & $0.34(0.05,2.17)$ & 0.25 & $0.23(0.02,2.35)$ & 0.21 \\
\hline \#Adjusted & $0.30(0.06,1.57)$ & 0.15 & $0.26(0.04,1.79)$ & 0.19 & $0.09(0.01,1.20)$ & 0.07 \\
\hline
\end{tabular}

Abbreviations: $B M I=$ body mass index; $E P C s=$ endothelial progenitor cells; $D B P=$ diastolic blood pressure; $h s$ - $C R P=$ High sensitivity $C$-reactive protein; $S B P=$ systolic blood pressure; $S O D=$ superoxide dismutase.

\#Adjusted for age, gender, BMI, smoking, hypertension, hypercholesterolaemia, hbA1c.

conditions [43]. This finding is further confirmed by the results of this study, suggesting the close interplay between oxidative stress and EPCs that independently contributes to myocardial dysfunction.

\section{Clinical implications}

The present study is the first to demonstrate that impaired myocardial function in patients with T2DM is independently associated with depletion of EPCs and increased oxidative stress. In animal studies, therapeutic interventions aimed at increasing EPCs and reducing oxidative stress improved myocardial function [4]. Future human studies should therefore aim to develop therapies that may reduce oxidative stress and/or recruit EPCs to prevent myocardial dysfunction in patients with T2DM.

\section{Limitations}

A causal relationship between CD34+ EPCs, SOD and impaired myocardial strain could not be established because of the cross-sectional nature of the study. Further, although patients with T2DM were all clinically free of cardiovascular complications, the presence of asymptomatic coronary artery disease could not be excluded. The small study population did not allow additional analysis of other mechanisms that could potentially contribute to myocardial dysfunction. In addition, the reason for the correlation of CD34+ EPCs and SOD with only global circumferential strain, not longitudinal and radial strains, is uncertain. The LV myocardial fibre architecture has a typical orientation of myocardial strands that change from being oblique in the subepicardium, to circumferential in the middle, and longitudinal in the subendocardium [44]. Thus, whether depletion of CD34+ EPCs and oxidative stress preferentially affects the mid-wall, rather than the subendocardium in these patients, requires further evaluation.

\section{Conclusions}

Patients with T2DM and no clinical evidence of macrovascular disease showed impaired myocardial strain detected by 2D speckle tracking derived strain analysis. Importantly, LV global circumferential strain was independently associated with both CD34+ EPCs and SOD. These findings suggest that myocardial dysfunction in patients with T2DM is related to depletion of EPCs and increased oxidative stress.

\section{Abbreviations}

2D: 2-dimensional; BMI: Body-mass index; EPCs: Endothelial progenitor cells; HDL-C: High-density lipoprotein-cholesterol; hs-CRP: High sensitivity Creactive protein; LDL-C: Low-density lipoprotein-cholesterol; LV: Left ventricular; SOD: Superoxide dismutase; T2DM: Type 2 diabetes mellitus.

\section{Competing interests}

The authors declare that there is no competing interest associated with this manuscript.

\section{Authors' contributions}

CTZ coordinated analyses, interpreted results and wrote the manuscript. MW performed statistical analyses and revised the manuscript. CWS advised and 
supervised statistical analyses and revised the manuscript. YLH and TW were involved in the conception and design of the study, interpretation of the data, ongoing support and advice to the first author. KHY contributed to study design, data interpretation and manuscript revision. HFT designed and led the project and revised the manuscript. All authors have approved the final version of the manuscript.

\section{Author details}

${ }^{1}$ Shan Dong University School of Medicine, Shandong, China. ${ }^{2}$ Division of Cardiology, Department of Medicine, the University of Hong Kong, Queen Mary Hospital, Rm 1929b, Block K, Hong Kong, China. ${ }^{3}$ Division of Cardiology, Traffic Hospital in Shan Dong Province, Shandong, China. ${ }^{4}$ Research Centre of Heart, Brain, Hormone and Healthy Aging, Li Ka Shing Faculty of Medicine, the University of Hong Kong, Hong Kong, China.

Received: 3 November 2012 Accepted: 27 November 2012 Published: 5 December 2012

\section{References}

1. Nichols GA, Gullion CM, Koro CE, Ephross SA, Brown JB: The incidence of congestive heart failure in type 2 diabetes: an update. Diabetes Care 2004, 27(8):1879-1884

2. Kannel WB, Hjortland M, Castelli WP: Role of diabetes in congestive heart failure: the Framingham study. Am J Cardiol 1974, 34(1):29-34.

3. Aksakal E, Akaras N, Kurt M, Tanboga IH, Halici Z, Odabasoglu F, Bakirci EM, Unal B: The role of oxidative stress in diabetic cardiomyopathy: an experimental study. Eur Rev Med Pharmacol Sci 2011, 15:1241-1246.

4. Yoon YS, Uchida S, Masuo O, Cejna M, Park JS, Gwon HC, Kirchmair R, Bahlman F, Walter D, Curry C, et al: Progressive attenuation of myocardial vascular endothelial growth factor expression is a seminal event in diabetic cardiomyopathy: restoration of microvascular homeostasis and recovery of cardiac function in diabetic cardiomyopathy after replenishment of local vascular endothelial growth factor. Circulation 2005, 111(16):2073-2085

5. Miki T, Yuda S, Kouzu H, Miura T: Diabetic cardiomyopathy: pathophysiology and clinical features. Hear Fail Rev 2012, [epud ahead of print].

6. Asahara T, Murohara T, Sullivan A, Silver M, van der Zee R, Li T, Witzenbichler B, Schatteman G, Isner JM: Isolation of putative progenitor endothelial cells for angiogenesis. Science 1997, 275:964-967.

7. Fadini GP, Mancuso P, Bertolini F, de Kreutzenberg S, Avogaro A Amelioration of glucose control mobilizes circulating pericyte progenitor cells in type 2 diabetic patients with microangiopathy. Exp Diabetes Res 2012, Epud ahead of print.

8. Cheng Y, Guo S, Liu G, Feng Y, Yan B, Yu J, Feng K, Li Z: Transplantation of bone marrow-derived endothelial progenitor cells attenuates myocardial interstitial fibrosis and cardiac dysfunction in streptozotocin-induced diabetic rats. Int J Mol Med 2012, Epud ahead of print

9. Ernande L, Bergerot C, Rietzschel ER, De Buyzere ML, Thibault $H_{\text {, }}$ Pignonblanc PG, Croisille P, Ovize M, Groisne L, Moulin P, et al: Diastolic dysfunction in patients with type 2 diabetes mellitus: is it really the first marker of diabetic cardiomyopathy? J Am Soc Echocardiogr 2011, 24(11):1268-1275. e1261.

10. Ng AC, Delgado V, Bertini M, van der Meer RW, Rijzewijk $\amalg$, Shanks $M$, Nucifora G, Smit JW, Diamant M, Romijn JA, et al: Findings from left ventricular strain and strain rate imaging in asymptomatic patients with type 2 diabetes mellitus. Am J Cardio/ 2009, 104:1398-1401.

11. Lau KK, Chan YH, Yiu KH, Li SW, Tam S, Lau CP, Kwong YL, Tse HF: Burden of carotid atherosclerosis in patients with stroke: relationships with circulating endothelial progenitor cells and hypertension. J Hum Hypertens 2007, 21(6):445-451.

12. Luk TH, Dai YL, Siu CW, Yiu KH, Chan HT, Fong DY, Lee SW, Li SW, Tam S, Lau CP, et al: Habitual physical activity is associated with endothelial function and endothelial progenitor cells in patients with stable coronary artery disease. Eur J Cardiovasc Prev Rehabil 2009, 16(4):464-471.

13. Dai YL, Luk TH, Yiu KH, Wang M, Yip PM, Lee SW, Li SW, Tam S, Fong B, Lau CP, et al: Reversal of mitochondrial dysfunction by coenzyme Q10 supplement improves endothelial function in patients with ischaemic left ventricular systolic dysfunction: a randomized controlled trial. Atherosclerosis 2011, 216:395-401.
14. Wong CY, Qiuwaxi J, Chen H, Li SW, Chan HT, Tam S, Shu XO, Lau CP, Kwong YL, Tse HF: Daily intake of thiamine correlates with the circulating level of endothelial progenitor cells and the endothelial function in patients with type II diabetes. Mol Nutr Food Res 2008, 52(12):1421-1427.

15. Yiu KH, Wang S, Mok MY, Ooi GC, Khong PL, Lau CP, Lai WH, Wong LY, Lam KF, Lau CS, et al: Role of circulating endothelial progenitor cells in patients with rheumatoid arthritis with coronary calcification. J Rheumatol 2010, 37(3):529-535.

16. McQuillan BM, Picard MH, Leavitt M, Weyman AE: Clinical correlates and reference intervals for pulmonary artery systolic pressure among echocardiographically normal subjects. Circulation 2001, 104(23):2797-2802

17. Nagueh SF, Appleton CP, Gillebert TC, Marino PN, Oh JK, Smiseth OA, Waggoner AD, Flachskampf FA, Pellikka PA, Evangelisa A:

Recommendations for the evaluation of left ventricular diastolic function by echocardiography. Eur J Echocardiogr 2009, 10(2):165-193.

18. Delgado V, Ypenburg C, van Bommel RJ, Tops LF, Mollema SA, Marsan NA, Bleeker GB, Schalij MJ, Bax JJ: Assessment of left ventricular dyssynchrony by speckle tracking strain imaging comparison between longitudinal, circumferential, and radial strain in cardiac resynchronization therapy. J Am Coll Cardiol 2008, 51(20):1944-1952.

19. Takigiku K, Takeuchi M, Izumi C, Yuda S, Sakata K, Ohte N, Tanabe K, Nakatani S, on behalf of the JUSTICE investigators: Normal Range of Left Ventricular 2-Dimensional Strain. Circ J 2012, Epud ahead of print.

20. Raimondi L, De Paoli P, Mannucci E, Lonardo G, Sartiani L, Banchelli G, Pirisino R, Mugelli A, Cerbai E: Restoration of cardiomyocyte functional properties by angiotensin II receptor blockade in diabetic rats. Diabetes 2004, 53:1927-1933.

21. Ng AC, Delgado $V$, Bertini M, van der Meer RW, Rijzewijk $L$, Hooi Ewe $S$, Siebelink HM, Smit JW, Diamant M, Romijn JA, et al: Myocardial steatosis and biventricular strain and strain rate imaging in patients with type 2 diabetes mellitus. Circulation 2010, 122:2538-2544.

22. Sacre JW, Franjic B, Jellis CL, Jenkins C, Coombes JS, Marwick TH: Association of cardiac autonomic neuropathy with subclinical myocardial dysfunction in type 2 diabetes. JACC CardiovasC Imaging 2010, 3:1207-1215.

23. Jellis C, Wright J, Kennedy D, Sacre J, Jenkins C, Haluska B, Martin J, Fenwick J, Marwick TH: Association of imaging markers of myocardial fibrosis with metabolic and functional disturbances in early diabetic cardiomyopathy. Circ Cardiovasc Imaging 2011, 6:693-702.

24. Andersson C, Gislason GH, Weeke P, Hoffmann S, Hansen PR, Torp-Pedersen C, Søgaard P: Diabetes is associated with impaired myocardial performance in patients without significant coronary artery disease. Cardiovasc Diabetol 2010, 18:3.

25. Laakso M: Heart in diabetes: a microvascular disease. Diabetes Care 2011, 34(Supplement 2):S145-S149.

26. Rubler S, Dlugash J, Yuceoglu YZ, Kumral T, Branwood AW, Grishman A: New type of cardiomyopathy associated with diabetic glomerulosclerosis. Am J Cardiol 1972, 30:595-602.

27. Kawaguchi M, Techigawara M, Ishihata T, Asakura T, Saito F, Maehara K, Maruyama Y: A comparison of ultrastructural changes on endomyocardial biopsy specimens obtained from patients with diabetes mellitus with and without hypertension. Hear Vessel 1997 $12: 267-274$.

28. De Lorenzo A, Lima RS, Siqueira-Filho AG, Pantoja MR: Prevalence and prognostic value of perfusion defects detected by stress technetium-99 m sestamibi myocardial perfusion single-photon emission computed tomography in asymptomatic patients with diabetes mellitus and no known coronary artery disease. Am J Cardiol 2002, 90:827-832

29. Hristov M, Erl W, Weber PC: Endothelial progenitor cells: mobilization, differentiation, and homing. Arterioscler Thromb Vasc Biol 2003, 23:1185-1189.

30. Urbich C, Aicher A, Heeschen C, Dernbach E, Hofmann WK, Zeiher AM, Dimmeler S: Soluble factors released by endothelial progenitor cells promote migration of endothelial cells and cardiac resident progenitor cells. J Mol Cell Cardiol 2005, 39:733-742.

31. Yue WS, Lau KK, Siu CW, Wang M, Yan GH, Yiu KH, Tse HF: Impact of glycemic control on circulating endothelial progenitor cells and arterial stiffness in patients with type 2 diabetes mellitus. Cardiovasc Diabetol 2011, 10:113. 
32. Palombo C, Kozakova M, Morizzo C, Gnesi L, Barsotti MC, Spontoni P, Massart F, Salvi P, Balbarini A, Saggese G, et al: Circulating endothelial progenitor cells and large artery structure and function in young subjects with uncomplicated type 1 diabetes. Cardiovasc Diabetol 2011, 10:88

33. Yiu YF, Chan YH, Yiu KH, Siu CW, Li SW, Wong LY, Lee SW, Tam S, Wong EW, Cheung BM, et al: Vitamin D deficiency is associated with depletion of circulating endothelial progenitor cells and endothelial dysfunction in patients with type 2 diabetes. J Clin Endocrinol Metab 2011, 96:E830-E835.

34. Fadini GP, Miorin M, Facco M, Bonamico S, Baesso I, Grego F, Menegolo M, de Kreutzenberg SV, Tiengo A, Agostini C, et al: Circulating endothelial progenitor cells are reduced in peripheral vascular complications of type 2 diabetes mellitus. J Am Coll Cardiol 2005, 45:1449-1457.

35. Fadini GP, Sartore S, Albiero M, Baesso I, Murphy E, Menegolo M, Grego F, Vigili de Kreutzenberg S, Tiengo A, Agostini C, et al: Number and function of endothelial progenitor cells as a marker of severity for diabetic vasculopathy. Arterioscler Thromb Vasc Biol 2006, 26(9):2140-2146.

36. Fadini GP, de Kreutzenberg S, Agostini C, Boscaro E, Tiengo A, Dimmeler S, Avogaro A: Low CD34+ cell count and metabolic syndrome synergistically increase the risk of adverse outcomes. Atherosclerosis 2009, 207:213-219.

37. Werner N, Kosiol S, Schiegl T, Ahlers P, Walenta K, Link A, Böhm M, Nickenig G: Circulating endothelial progenitor cells and cardiovascular outcomes. N Eng J Med 2005, 353:999-1007.

38. Yeh ET, Zhang S, Wu HD, Körbling M, Willerson JT, Estrov Z: Transdifferentiation of human peripheral blood CD34 + -enriched cell population into cardiomyocytes, endothelial cells, and smooth muscle cells in vivo. Circulation 2003, 108:2070-2073.

39. Fadini GP, de Kreutzenberg SV, Coracina A, Baesso I, Agostini C, Tiengo A, Avogaro A: Circulating CD34+ cells, metabolic syndrome, and cardiovascular risk. Eur Heart J 2006, 27:2247-2255.

40. Brownlee M: Biochemistry and molecular cell biology of diabetic complications. Nature 2001, 414:813-820.

41. Huynh K, Kiriazis H, Du XJ, Love JE, Jandeleit-Dahm KA, Forbes JM, McMullen JR, Ritchie RH: Coenzyme Q10 attenuates diastolic dysfunction, cardiomyocyte hypertrophy and cardiac fibrosis in the $\mathrm{db} / \mathrm{db}$ mouse model of type 2 diabetes. Diabetologia 2012, 55:1544-1553.

42. Khong FL, Zhang Y, Edgley AJ, Qi W, Connelly KA, Woodman OL, Krum H, Kelly DJ: 3/,4/-Dihydroxyflavonol antioxidant attenuates diastolic dysfunction and cardiac remodeling in streptozotocin-induced diabetic m(Ren2)27 rats. PLoS One 2011, 6:e22777.

43. Hamed S, Brenner B, Aharon A, Daoud D, Roguin A: Nitric oxide and superoxide dismutase modulate endothelial progenitor cell function in type 2 diabetes mellitus. Cardiovasc Diabetol 2009, 8:56.

44. Ho SY: Anatomy and myoarchitecture of the left ventricular wall in normal and in disease. Eur J Echocardiogr 2009, 10:iii3-iii7.

doi:10.1186/1475-2840-11-147

Cite this article as: Zhao et al:: Myocardial dysfunction in patients with type 2 diabetes mellitus: role of endothelial progenitor cells and oxidative stress. Cardiovascular Diabetology 2012 11:147.

\section{Submit your next manuscript to BioMed Central and take full advantage of:}

- Convenient online submission

- Thorough peer review

- No space constraints or color figure charges

- Immediate publication on acceptance

- Inclusion in PubMed, CAS, Scopus and Google Scholar

- Research which is freely available for redistribution

Submit your manuscript at www.biomedcentral.com/submit
Ciomed Central 